\title{
O papel do
}

\section{Brasil no}

\section{estabelecimento}

\section{do mercado}

\section{internacional de}

\section{biocombustíveis}




\section{INTRODUÇÃ̃o}

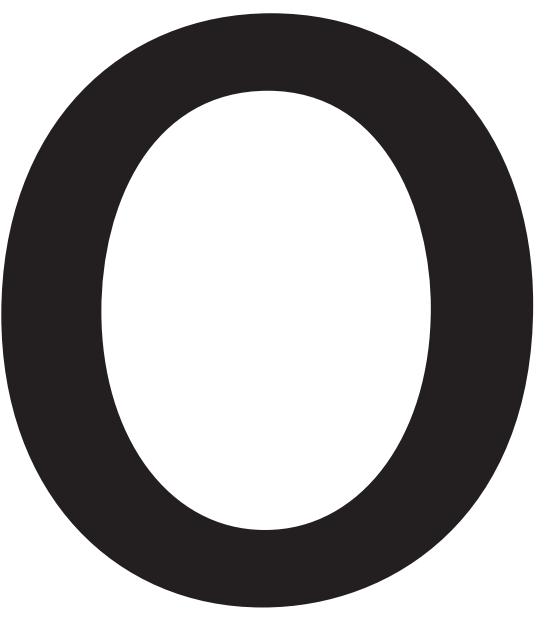

presidente da Federação das Indústrias do Estado de São Paulo (Fiesp), Paulo Skaf, escreveu em artigo na Folha de S. Paulo, de 31/7/2007, intitulado "Argumentos Voláteis", sobre as barreiras ainda existentes ao mercado internacional de biocombustíveis: “À luz do bom senso, não se pode admitir que o mundo desenvolvido, que já devastou a grande maioria de suas flores-

tas, é o maior emissor de gases de efeito estufa e agente das mudanças climáticas, coloque obstáculos à transformação dos biocombustíveis em commodities internacionais".

As cadeias produtivas dos biocombustíveis no Brasil se preparam para a diminuição das barreiras de mercado às quais Skaf se refere e o amadurecimento do mercado internacional. A demanda foi estabelecida principalmente pelas políticas públicas relacionadas à substituição de combustíveis fósseis por renováveis, adotadas por países em todo o mundo, sendo as mais relevantes até o momento, considerando o volume demandado em curto prazo, as políticas da União Européia e dos Estados Unidos.

O objetivo deste artigo é esclarecer as potencialidades dos biocombustíveis como substituto de parte dos combustíveis fósseis e a oportunidade para a economia brasileira, por meio de um panorama do mercado global. O artigo está dividido em seis partes, sendo a primeira e a última breves introdução e conclusão. A segunda seção apresenta os principais mercados atuais para biocombustíveis, que foram criados principalmente a partir de legislações específicas instauradas nos Estados Unidos e na União Européia. Na terceira parte são descritas as vantagens e desvantagens dos biocombustíveis produzidos hoje no mundo e procura-se deix ar claro que esses aspectos variam muito conforme a matéria-prima que é empregada e a região onde são produzidos. Na quarta parte são descritos o contexto brasileiro de produção e uso de biocombustíveis e as políticas públicas dedicadas ao setor. Na quinta seção são apresentados os aspectos que influenciam a constituição do mercado internacional para biocombustíveis e como o Brasil pode se beneficiar do estabelecimento desse mercado.

\section{O MERCADO INTERNACIONAL DE BIOCOMBUSTIVEEIS}

A discussão sobre biocombustíveis tomou proporções nunca antes vistas na sociedade nos últimos anos. No Brasil estamos acostumados com a periódica entrada e saída do álcool das pautas do jornalismo nas últimas décadas, porém, nos últimos três anos fomos inundados com informações sobre o estabelecimento do mercado global de álcool e biodiesel. Isso se deve principalmente ao fato de a Europa e os Estados Unidos terem adotado políticas de incentivo à produção e consumo de biocombustíveis como uma forma de substituir parte do consumo de combustíveis fósseis, um esforço para reduzir a emissão dos gases do efeito estufa e a dependência de combustíveis com preços crescentes, fornecidos por países politicamente instáveis.

A Diretiva 2003/30/CE do Parlamento Europeu, de 8 de maio de 2003, relativa à promoção do uso de biocombustíveis ou de outros combustíveis renováveis nos transportes, determina a substituição de 5,75\% dos combustíveis fósseis por renováveis pelos países membros da União Européia (UE) até 2010. Na UE, a substituição não é compulsória, mas há pressões políticas previstas aos países que não adotarem medidas específicas para atingir as metas estipuladas.

Nos Estados Unidos, as diversas legislações de incentivo ao etanol surgiram devido a questões ambientais e de saúde pública relacionadas ao uso do MTBE (metil- tercbutil éter) como aditivo à gasolina. O MTBE 
atua como um oxigenante, importante para a queima eficiente do combustível, porém é tóxico ao homem e, quando derramado, é extremamente poluente. Está sendo substituído pelo ETBE, derivado do etanol, que é renovável e não é tóxico. A substituição de parte dos combustíveis fósseis é também motivada pela redução da dependência de países produtores de combustível. Por último, os países que adotam os biocombustíveis têm a oportunidade de aprimorar suas políticas agrícola e industrial, sendo que nos Estados Unidos isso ocorre através do estímulo à produção de milho e à indústria do etanol.

Após a publicação do Terceiro Relatório do Painel Intergovernamental sobre Mudanças Climáticas (IPCC), em julho de 2001, no qual a comunidade científica reconheceu a ocorrência do aquecimento global e a possibilidade de detê-lo através da redução imediata das emissões dos gases do efeito estufa (GEE), os governos passaram a tomar medidas nesse sentido. A entrada em vigor do Protocolo de Kyoto, em 2005, com o comprometimento de 125 países industrializados em reduzir suas emissões de $\mathrm{CO}_{2}$, acelerou o processo de substituição gradual do uso de combustíveis fósseis por renováveis.

Os biocombustíveis já são uma realidade no setor de transportes, um dos maiores emissores de GEE. São as melhores alternativas imediatas à gasolina e ao diesel já que outras opções, como células de hidrogênio, só devem estar disponíveis em larga escala no mercado em médio prazo.

Espera-se, então, que o mercado para biocombustíveis se consolide em longo prazo. No momento esse mercado ainda é pequeno já que se baseia no consumo da produção interna de cada país, exceto por um reduzido mercado internacional para o álcool. No ano passado o Brasil exportou 3,4 bilhões de litros de álcool, sendo 1,76 bilhão para os Estados Unidos, 591 milhões para a União Européia (principalmente Países Baixos e Suécia) e 225 milhões para o Japão.

Ademanda dos países da América Latina pelo álcool brasileiro foi de 657 milhões de litros; porém, quase metade desse volume foi direcionada para os Estados Unidos. Isso ocorreu a fim de se aproveitar as vantagens de acesso de alguns países da América Central a esse mercado, através do Tratado de Livre Comércio com a América Central (Costa Rica, El Salvador, Guatemala, Honduras, Nicarágua e República Dominicana). O álcool hidratado brasileiro é utilizado como matéria-prima para a produção de álcool anidro nesses países, posteriormente vendido para os Estados Unidos. Essa opção deve ser mais explorada no futuro através de acordos entre esses países e o Brasil.

O consumo na América Latina, por sua vez, tem potencial de crescimento, principalmente neste momento de insegurança no fornecimento de combustíveis fósseis. O Chile já anunciou que irá misturar 5\% de etanol à gasolina em curto prazo, e pretende até mesmo importar carros flex fuel.

Como conseqüência da aplicação em larga escala dos biocombustíveis no mundo, a discussão sobre suas vantagens e desvantagens se ampliou, envolvendo especialistas que questionam suas reais potencialidades em reduzir os impactos ambientais e beneficiar o desenvolvimento econômico e social dos países. A seção a seguir não pretende esgotar a discussão, mas sim levantar alguns fatores importantes que devem ser analisados com clareza.

\section{VANTAGENS E DESVANTAGENS DA SUBSTITUIÇ̃̃O DOS COMBUSTIVEEIS FÓSSEIS POR BIOCOMBUSTIVEEIS}

Como foi dito anteriormente, o mercado internacional para biocombustíveis é ainda irrisório, estando restrito praticamente à exportação de álcool brasileiro. Mesmoessa pequena quantidade está ameaçada de não conseguir atingir seus mercados de destino pois as tarifas impostas pelos importadores são tão altas que só se torna viável a venda quando os preços do álcool atingem pa- 
tamares muito elevados, como aconteceu no mercado norte-americano em 2006. O álcool produzido a partir de cana-de-açúcar conseguiu ser competitivo no mercado dos Estados Unidos mesmo com os vultosos subsídios e as taxas de importação.

Nesse país o álcool é produzido a partir de milho, que tem balanço energético baixo, quando comparado ao de cana-de-açúcar, porque a conversão da planta em energia é baixa, além de a produção ser dependente de grandes quantidades de insumos agrícolas, tais como fertilizantes e defensivos. Segundo estudo feito pela Organização para a Cooperação e o Desenvolvimento Econômico (OECD, em inglês) em 2004, para cada unidade de energia fóssil investida, é produzida entre 1,25 e 1,66 unidade de energia renovável, enquanto no caso do álcool de cana-de-açúcar resultam entre 8,3 e 10,2 unidades. Esse é apenas um dos indicadores que apontam para o potencial incomparável da cana-de-açúcar para a produção de energia. A cana-de-açúcar é uma cultura tropical e, de maneira geral, regiões tropicais têm maior potencial para a produção de biomassa e apresentam rendimentos agrícolas superiores aos obtidos nos países de clima temperado.

O comportamento dos Estados Unidos de produzir seu próprio combustível renovável se repete na Europa, em detrimento de importá-lo de países localizados em latitudes mais baixas. A produtividade nessas regiões é muito baixa, como foi dito no parágrafo anterior, e as vantagens ambientais discutíveis. Os questionamentos que se ouvem hoje na esfera internacional são plenamente cabíveis nesses casos, porém devem considerar que os rendimentos obtidos em países tropicais tornam esses casos algo à parte. No entanto, é paradoxal o comportamento da sociedade européia, que dificilmente aceitará consumir um combustível importado sem certificação de sustentabilidade ambiental e social, enquanto o biocombustível que é consumido internamente demandou intenso uso de fertilizantes químicos e defensivos agrícolas que resultam em um rendimento pífio de energia ao final do processo.
Uma das explicações para esse comportamento contraditório está na inserção dos biocombustíveis em políticas que não estão relacionadas ao ambiente e, nesse caso, a certificação teria o papel de criar uma barreira ao invés de garantir a sustentabilidade do produto, como será visto mais adiante. A opção pela não importação em grande escala está relacionada em parte às políticas agrícolas e industriais desses países, que visam a proteger o mercado interno dos produtos importados, mais competitivos. A consequiência disso é o uso de produtos menos sustentáveis que comprometem o impacto das políticas ambientais (que visam à redução da emissão dos gases do efeito estufa) e de desenvolvimento econômico, principalmente de países em desenvolvimento com vantagens competitivas.

As principais críticas dirigidas hoje à produção de biocombustíveis estão relacionadas ao seu baixo rendimento energético em relação a fontes fósseis, à competição por fatores de produção de alimentos, tais como terra e água, e destruição de ecossistemas. Em artigo da revista Energy Policy, publicado em 27 de março de 2007, John A. Mathews, da Universidade de Macquarie, Austrália, responde a essas críticas argumentando que elas só fazem sentido dentro dos contextos agrícolas europeu e norte-americano de produção. Acompetição por terras para a produção de alimentos e o desempenho irrisório do balanço energético são conseqüências do baixo potencial dessas regiões de produzir biomassa e da falta de disponibilidade de terras agricultáveis para expansão da produção, fatores esses que não refletem a condição nos países em desenvolvimento. Segundo a Organização das Nações Unidas para a Agricultura e Alimentação (FAO, em inglês - ftp://ftp. fao.org/agl/agll/docs/wsr.pdf), 70\% do potencial para expansão agrícola no mundo está na África subsaariana e nas Américas Central e do Sul.

A solução que Mathews apóia para o uso sustentável dos biocombustíveis foi proposta pelo diretor executivo da Agência Internacional de Energia (IEA), Claude Mandil. Essa estratégia consiste em que os 
países desenvolvidos do hemisfério norte façam um pacto com os países em desenvolvimento do sul para o fornecimento de biocombustíveis em larga escala. Esse pacto estabeleceria um marco regulatório internacional, com sistema de certificação de qualidade e desempenho ambiental. Em contrapartida, os países produtores de biocombustíveis teriam acesso garantido de seu produto aos principais países consumidores de combustíveis líquidos além de contar com cooperação tecnológica internacional.

Os principais argumentos a favor dos biocombustíveis estão relacionados à comparação com o uso dos derivados do petróleo, considerando que uns são substitutos diretos dos outros. Oleque de mazelas do uso de combustíveis fósseis vai desde a emissão de gases do efeito estufa, dependência de países politicamente instáveis, em constantes conflitos bélicos e que ameaçam os direitos humanos, chegando até a natureza da produção que inevitavelmente gera concentração de renda nos países produtores. Além disso, os constantes aumentos nos preços mundiais desse produto são resultado de sua irreversível escassez, o que ameaça as balanças comerciais de todos os países dependentes de importação.

Os biocombustíveis, ao contrário, têm o potencial de promover o desenvolvimento de países a partir do aprimoramento das cadeias produtivas agroindustriais, desde que respaldados por políticas públicas sólidas e devidamente monitoradas. Para apoiar esses argumentos, a experiência brasileira com biocombustíveis e a participação que esses têm hoje em sua economia devem servir de modelo. A seguir é apresentado o contexto brasileiro de produção e uso de biocombustíveis, as políticas públicas que amparam o setor, além das oportunidades e fraquezas existentes nessas cadeias produtivas.

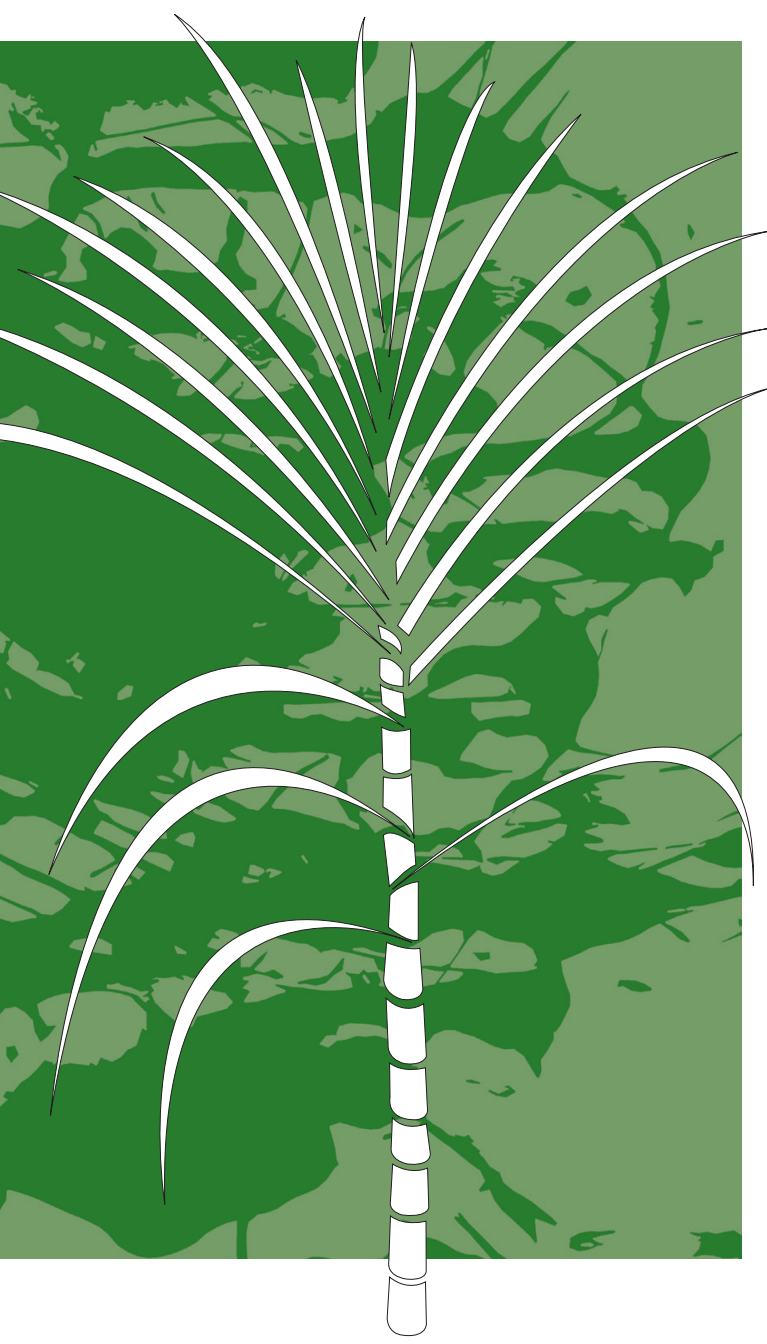

\section{O CONTEXTO BRASILEIRO DE PRODUÇÃO E USO DOS BIOCOMBUSTIVEIS}

O Brasil hoje lidera o movimento de países a favor do uso em grande escala dos biocombustíveis. É o país que tem a experiência mais antiga e relevante de produção e uso desses energéticos. Segundo o Ministério de Minas e Energia (MME), no setor de transportes, $20 \%$ do consumo é representado por combustíveis renováveis, maior participação do mundo, o que faz do país o melhor estudo de caso para avaliar a viabilidade de seu uso em larga escala.

As políticas públicas mais recentes de estímulo aos biocombustíveis estão inseridas no Programa Nacional de Produção e Uso do Biodiesel (PNPB), instituído pelo Decreto 0-002 de 2 de julho de 2003, através da criação do Grupo de Trabalho Interministerial, responsável por pensar o programa e determinar quais ações seriam tomadas. $\mathrm{O}$ resultado foi a efetivação da Lei no 11.097, 
de 2005, que dispõe sobre a introdução do biodiesel na matriz energética brasileira, determinando sua mistura compulsória a todo diesel comercializado no país a um teor de $2 \%$ a partir de 2008 e de $5 \%$ a partir de 2013. Para que a agricultura familiar fosse inserida nesse processo de expansão da lavoura energética, foram inseridos três mecanismos: o selo "combustível social”; os descontos nos impostos federais (PIS/Pasep e Cofins) conforme região, sistema de produção e matéria-prima de que foi originado o biodiesel; e os leilões coordenados pela Agência Nacional de Petróleo, Gás Natural e Biocombustíveis (ANP).

O selo "combustível social" pode ser conquistado pelos produtores de biodiesel que adquirirem uma porcentagem mínima da matéria-prima utilizada da agricultura familiar. A porcentagem mínima varia por região: 50\% na Região Nordeste e Semiárido, $10 \%$ no Norte e Centro-Oeste, e 30\% no Sudeste e Sul. Os agricultores fornecedores devem ter acesso ao crédito previsto pelo Programa Nacional de Fortalecimento da Agricultura Familiar (Pronaf) e ter uma série de garantias firmadas em contrato de compra, que garantam o preço e volume a serem praticados, além de receber assessoria técnica do comprador.

Os produtores de biodiesel que possuem o selo têm descontos na tributação federal incidente e podem participar dos leilões organizados pela ANP. Nesses leilões, as produtoras e importadoras de diesel no país (a Petrobras representa 93\% desse mercado) são responsáveis por comprar toda a quantia que a ANP determina como meta a ser leiloada. Até este ano, a meta era de 840 milhões de litros, volume necessário para a produção do B2 (diesel com $2 \%$ de biodiesel) em todo o país, que será obrigatória a partir do próximo ano. Novos leilões devem ser organizados a partir do ano que vem com o objetivo de preparar o mercado para a produção do B5.

Por último, o desconto nos impostos federais incidentes sobre o biodiesel produzido no Norte e Nordeste, a partir de mamona ou dendê e proveniente da agricultura familiar, visa a beneficiar regiões carentes e culturas que demandam uso intensivo de mão-de-obra. No momento, falta uma política dos estados de desconto do ICMS, que faz com que o biodiesel seja hoje o segundo combustível mais onerado, perdendo somente para a gasolina.

No caso do álcool, a cadeia produtiva é bem mais antiga. Foi impulsionada principalmente pelo Programa Nacional do Álcool (Proálcool) em 1975, mesma época em que surgiu o Proóleo, embrião do atual programa para o biodiesel, que não foi para a frente. No entanto, o país possui política específica para a produção e uso do álcool como combustível desde a década de 1930. Até a década de 1990, quando ocorreu a desregulamentação do setor, a quantidade produzida de cana-de-açúcar, açúcar e álcool e os preços praticados eram controlados pelo Estado, que direcionou vultosos subsídios ao setor. A pesquisa e o desenvolvimento tecnológico dependeram tanto do financia-

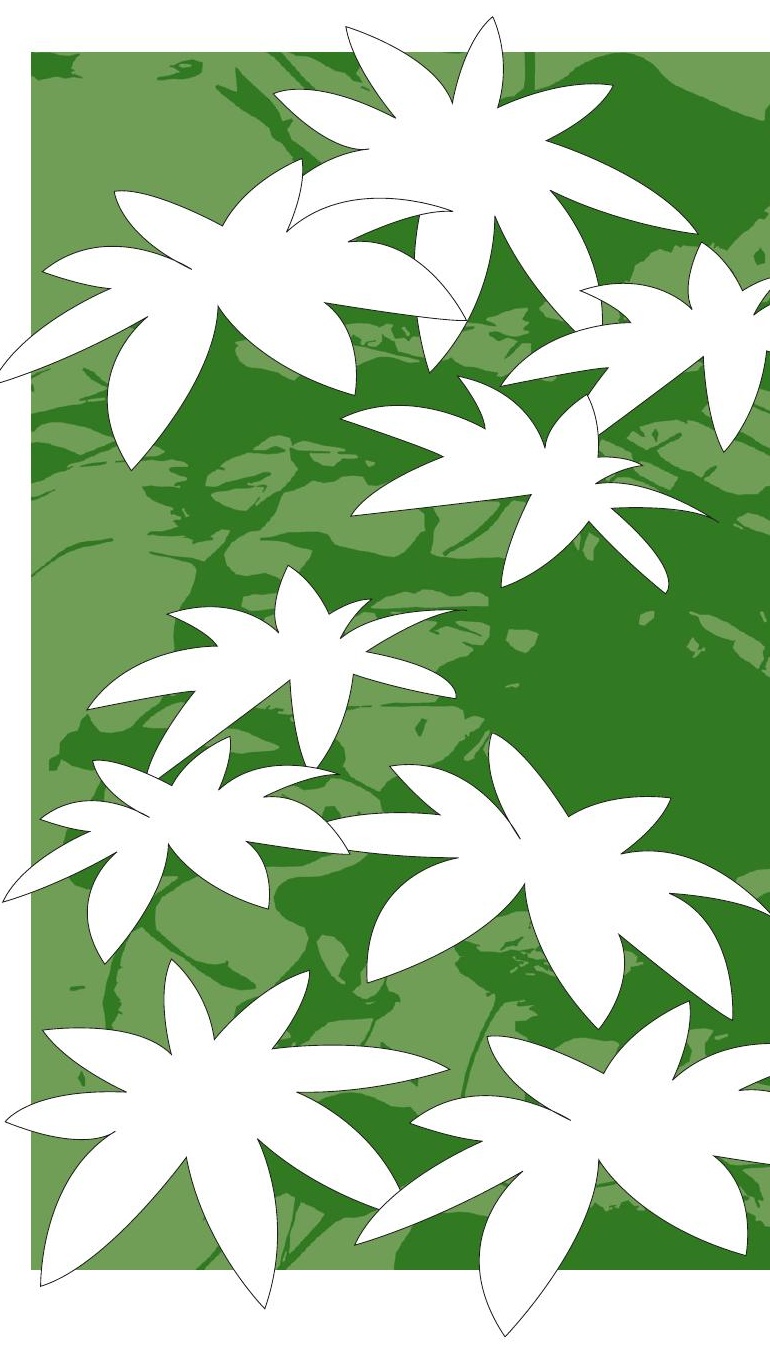


mento público quanto privado e resultaram em um produto com preço competitivo com a gasolina em algumas regiões.

Após a desregulamentação do setor, produtores de cana-de-açúcar e a indústria tiveram de se organizar para criar um sistema de formação de preço da canade-açúcar sendo que até aquele momento era papel do Estado defini-los. Existe uma interdependência entre os produtores e a usina mais próxima porque o transporte da cana-de-açúcar por grandes distâncias encarece o processo produtivo a ponto de torná-lo economicamente inviável.

Como conseqüência, o Conselho dos Produtores de Cana do Estado de São Paulo (Consecana) foi criado por representantes dos produtores agrícolas (Organização de Plantadores de Cana do Estado de São Paulo - Orplana) e industriais (União da Agroindústria Canavieira do Estado de São Paulo-Unica), que entraram em um acordo para criar o sistema Consecana. Hoje, quase toda a cana-de-açúcar do país é precificada através desse sistema, em que uma fórmula matemática calcula o preço dos açúcares totais redutores (ATR) presentes na canade-açúcar com base nos preços vigentes de açúcar e álcool no mercado recente.

A qualidade da cana-de-açúcar e o teor de ATR são analisados na porta da usina, processo que pode ser acompanhado por representantes dos produtores. Todo esse sistema somente foi passível de ser montado graças à organização do setor na forma de associações classistas e cooperativas. Regiões comoa de Piracicaba, graças a esse complexo sistema de organização, apresentam pequenos e médios produtores de cana-de-açúcar que fornecem $80 \%$ de toda a matéria-prima que as usinas da região adquirem no mercado, proveniente de unidades produtivas de até 50 hectares. A própria indústria produz aproximadamente metade da matéria-prima que processa nessa região.

A experiência da região de Piracicaba, uma das áreas tradicionais produtoras do estado de São Paulo, hoje evolui para a convergência das cadeias produtivas do biodiesel e do álcool para benefício dos agricultores cooperados e do parque indus- trial. Como consequiência, aprimora o setor de prestação de serviços e a organização do mercado, processo que foi acelerado pela criação do Arranjo Produtivo Local do Álcool (Apla).

A Cooperativa dos Plantadores de Cana de Piracicaba (Coplacana) está construindo uma planta industrial de biodiesel, para a qual os agricultores que plantarem uma oleaginosa na rotação da cana-de-açúcar (prática comum em outras regiões e benéfica para o solo) poderão entregar o produto. Em troca, a cooperativa fornecerá biodiesel para uso nos tratores e ração animal para os cooperados pecuaristas, proveniente do farelo restante após a retirada do óleo do grão, que entra como insumo na fábrica de ração que já possuem.

Não pode ser ignorado o fato de que em diversas regiões do Brasil, principalmente naquelas onde há a expansão da fronteira da cana-de-açúcar, existe também um processo de concentração de terras e, conseqüentemente, da renda. No entanto, esse é um fator relacionado à falta de planejamento e ordenamento territorial, e não à natureza do sistema de produção da cultura. As pequenas propriedades produtoras de cana-de-açúcar localizadas na Região Sudeste são resultado da fragmentação das propriedades rurais. Os agricultores permanecem na terra e conhecem bem a cultura, e estão tradicionalmente organizados em cooperativas e associações. Nas novas áreas é necessário uma intensa assessoria técnica para a introdução da cultura, além de colaboração para a organização dos agricultores. Isso é papel do Estado que reconhece a função social da agricultura e se esforça para evitar que o agricultor simplesmente arrende a terra e se mude para as cidades próximas ou, na pior hipótese, venda a área.

A organização dos produtores rurais em associações de forma a produzirem matériaprima é de interesse da indústria, que pode adquirir parte da cana-de-açúcar no mercado, não tendo de gerenciar uma área muito extensa requerida para abastecer a unidade de processamento. $\mathrm{O}$ associativismo se tornará ainda mais importante quando entrar em vigor a proibição da queimada na cana 
no estado de São Paulo, porque diversas propriedades terão que administrar o compartilhamento de uma colhedora.

Os aspectos descritos acima são insuficientes para demonstrar quantas oportunidades existem de gerar desenvolvimento a partir da exploração dessas cadeias produtivas. Atualmente, surgem periodicamente casos bem-sucedidos, inclusive em pequena e média escala, de uso de resíduos agrícolas, industriais e de dejetos urbanos para a produção de energia e geração de renda. Descrevê-los aqui tornaria o assunto muito extenso, mas exemplos de políticas governamentais e de iniciativas autônomas dos produtores podem servir de casos a serem replicados visando ao desenvolvimento econômico e social das regiões onde essas cadeias produtivas estão sendo instaladas. O Serviço Brasileiro de Apoio às Micro e Pequenas Empresas (Sebrae) estuda hoje a possibilidade de mapear algumas iniciativas que mereceriam ser replicadas, de forma a facilitar sua divulgação.

O primeiro levantamento da Companhia Nacional de Abastecimento (Conab) indica que nessa safra está sendo cultivada uma área 7,4\% maior de cana-de-açúcar que na safra passada. São 6,6 milhões de hectares, sendo $82,5 \%$ localizados na Região Centro-Sul do país, onde ocorre uma expansão principalmente para antigas áreas de pastagens. Pouco mais da metade da cana colhida é utilizada para a produção de álcool, que crescerá 14,54\% nessa safra, para 20,01 bilhões de litros, sendo que 91,20\% são oriundos da Região Centro-Sul.

A demanda interna tem crescido devido ao aumento da frota, principalmente de carros flex fuel; porém, o crescimento é restrito à Região Sudeste, que concentra a frota mais relevante e produz um álcool competitivo. Nesse ponto é importante esclarecer que a tecnologia e a infra-estrutura de produção foram desenvolvidas principalmente para atender à Região Sudeste, mais precisamente o estado de São Paulo, que hoje apresenta as produtividades mais altas do país devido ao uso de variedades especialmente desenvolvidas para as condições climáticas da região, além de estar próximo aos centros fornecedores de insumos agrícolas e possuir mão-de-obra capacitada em grande quantidade. O país enfrenta agora o desafio de disseminar a tecnologia de produção de cana-de-açúcar pelo mundo e, principalmente, pelo próprio Brasil, em estados que não são produtores tradicionais ou regiões que apresentam produtividades baixas e custos de produção altos.

Quanto ao biodiesel, foram comercializados 885 milhões de litros nos cinco leilões que já ocorreram, a serem entregues até o final deste ano. Porém, a ANP registrou, por enquanto, somente 190,8 milhões de litros produzidos desde 2005. A capacidade produtiva a ser instalada até o final do ano é de 1,3 bilhão de litros e os empreendimentos em fase de projeto podem levar a capacidade produtiva a 4 bilhões de litros nos próximos quatro anos.

O volume necessário para substituir todo o diesel por B2 a partir de 2008 é de 840 milhões de litros e, por B5, é de 2 bilhões de litros. A capacidade que está sendo instalada é muito maior que o mercado interno previsto em curto prazo, que está restrito à produção da mistura compulsória prevista em lei enquanto o biodiesel não for competitivo com o diesel. Isso acontece porque os investidores visam à reserva de mercado para atender as projeções futuras de demanda internacional, principalmente da Europa, que tem a frota mais expressiva de carros de ciclo diesel. A expansão do mercado interno se dará quando o melhoramento agronômico de matérias-primas mais produtivas em óleo, tais como o pinhãomanso, tornar o biodiesel competitivo, assim como o álcool hidratado se tornou depois de mais de 30 anos de pesquisas. Já existem empreendimentos em fase de projeto, em associação entre empresas nacionais e estrangeiras, para a produção voltada para o mercado externo.

A capacidade produtiva instalada está operando muito abaixo do seu máximo. Os possíveis motivos são: o mercado ainda não existe fora dos leilões porque a mistura ainda não é obrigatória e o biodiesel é mais caro que o diesel; o fluxo de matéria-prima ainda é incerto pois obiodiesel concorre por 


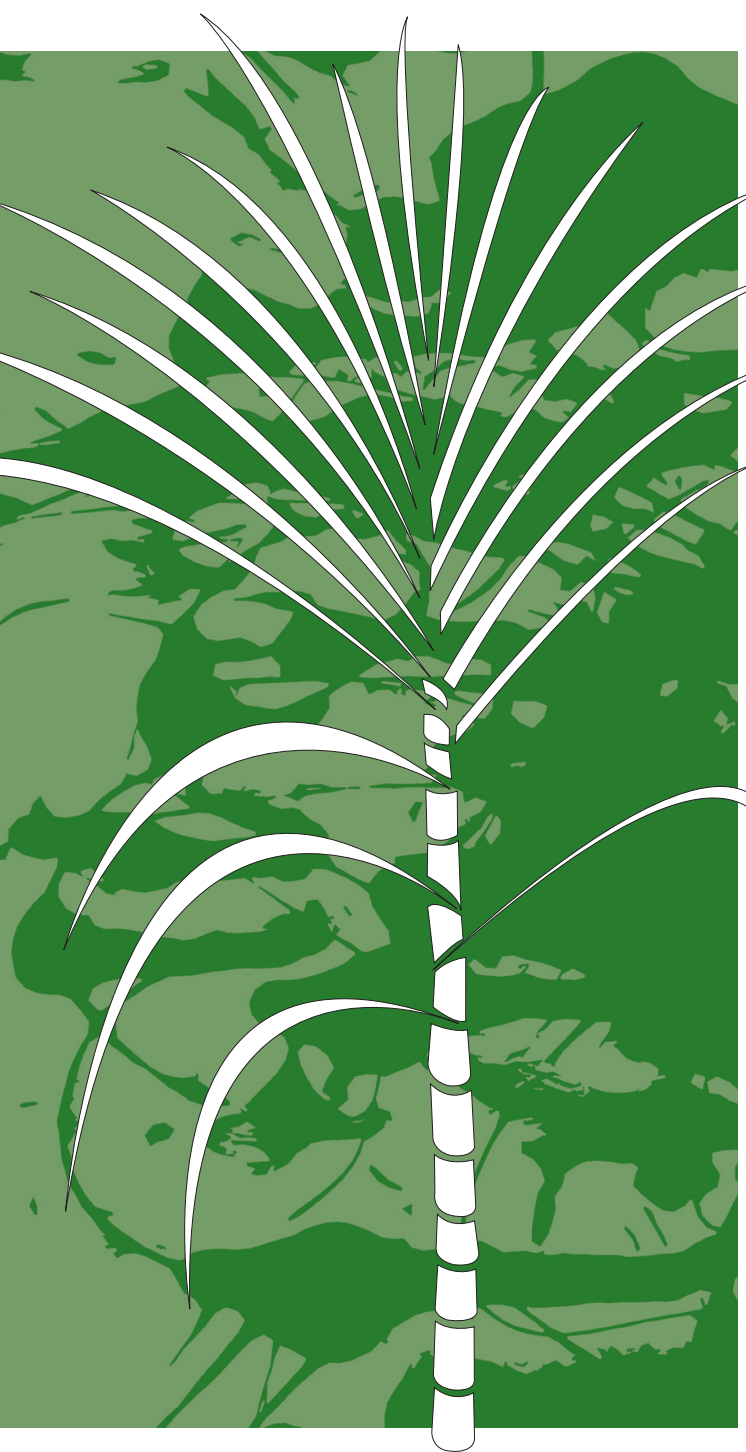

matéria-prima com o mercado de alimentos (e químico, no caso da mamona), que em condições normais oferece margens mais atraentes; as plantas industriais estão ainda em fase de aprimorar seus processos produtivos para alcançar as especificações de qualidade exigidas pela ANP; o comércio de biodiesel está acontecendo de forma irregular sem ser registrado pela ANP. Quanto aos principais avanços tecnológicos, no Brasil está sendo desenvolvido o sistema de produção pela rota etílica, que requer ainda alguns ajustes para passar a ser vantajoso quando comparado ao uso do metanol como reagente. As principais vantagens do uso do etanol são a abundância no mercado e preços atraentes, além de ser uma fonte de energia renovável que aprimora o balanço energético do combustível final.
Para atingir as produtividades agrícolas e rendimentos industriais que o país apresenta hoje foram empregados métodos de pesquisa e desenvolvimento considerados convencionais, tais como o melhoramento genético de variedades agrícolas através da seleção de linhagens mais aptas. No momento o mercado se prepara para um crescimento abrupto na produtividade dos biocombustíveis e aumento da disponibilidade de matérias-primas para esse fim provenientes do emprego de técnicas nãoconvencionais, tais como a transgenia e o uso de enzimas para a produção de açúcares simples para a produção de álcool. Detalhes sobre essas novas tecnologias e seus impactos na produção de biocombustíveis e no mercado brasileiro serão apresentados na seção a seguir.

\section{ASPECTOS TECNOLÓGICOS, TÉCNICOS E POLLITICOS QUE INFLUENCIARÃO 0 MERCADO}

\section{INTERNACIONAL DE BIOCOMBUSTIVEIS}

Todas as políticas públicas implantadas hoje pelo mundo relacionadas à inserção de biocombustíveis na matriz energética incentivam a produção e uso de um produto não-competitivo. Os combustíveis renováveis são mais caros que os fósseis em sua maior parte. Existem duas justificativas para essa atitude: são reconhecidas suas vantagens relativas e, principalmente, esses produtos são viáveis de se tornarem competitivos conforme caminhamos na curva de aprendizado.

O melhoramento de culturas específicas para o aproveitamento energético é algo que será de grande importância para essa cadeia produtiva, até mesmo para garantir o suprimento para as plantas de produção de biocombustíveis, de forma a não ter que competir por matéria-prima com a indústria 
de alimentos. O melhor exemplo de esforço nesse sentido é a pesquisa sobre pinhãomanso que ocorre em todo mundo para possibilitar o aproveitamento dessa cultura perene de alto rendimento em óleo.

Porém, a grande quebra de produtividade será resultado do uso comercial do que são hoje chamados biocombustíveis de segunda geração. São constituídos principalmente do álcool a partir da lignocelulose (presente em toda biomassa vegetal) e transformação da biomassa em líquido, processo batizado de BtL (biomass to liquid), que utiliza rejeitos tais como caules e raízes de milho, enquanto a espiga segue para a indústria de alimentos. Outras opções são o uso em maior escala de biogás (gás metano, principalmente, resultante da decomposição biológica da biomassa em aterros sanitários, granjas de suínos ou em qualquer outro depósito de resíduos orgânicos), bioquerosene de aviação, que já é desenvolvido no Brasil e testado no exterior, entre outros.

Para o Brasil é uma grande oportunidade poder disseminar a tecnologia de produção de álcool de cana-de-açúcar e, futuramente, de biodiesel. No caso doálcool, um mercado internacional para esse combustível requer, entre outros fatores, alguma diversidade de fornecedores que garantam suprimento regular de grandes volumes, sem causar dependência de um só fornecedor. Nesse contexto, seja através do memorando de entendimento entre países, como ocorreu entre os Estados Unidos e o Brasil, ou através de contratos diretos com empresas privadas, há inúmeras oportunidades de negócios envolvendo construção de usinas, constituição da lavoura canavieira, gerenciamento dos empreendimentos, venda de carros flex fuel, entre outros.

A cana-de-açúcar não perderá seu status de cultura de maior potencial para produção de biocombustíveis nem mesmo quando os de segunda geração passarem a ser explorados comercialmente, já que é a cultura de maior potencial de produção de biomassa por hectare do planeta. Sendo assim, o Brasil não perderá a vantagem de ser detentor da experiência com essa cultura. Para a lignocelulose ser aproveitada como

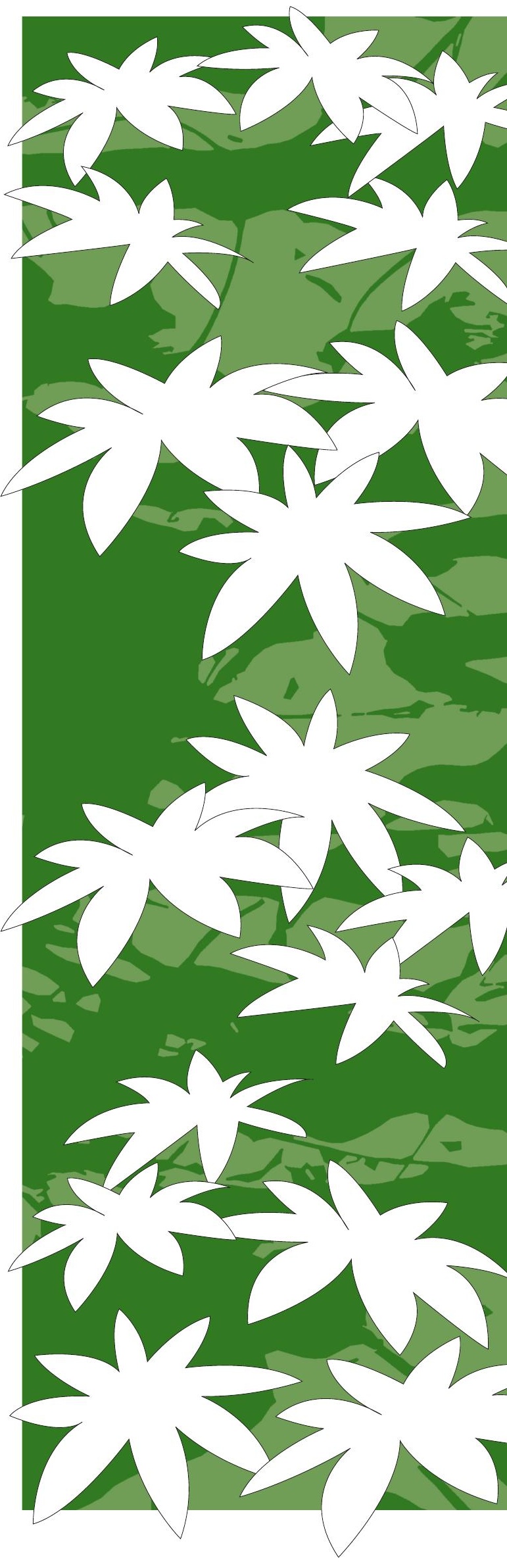


matéria-prima para a produção de álcool, ela tem de ser tratada para ser degradada em açúcares mais simples, passíveis de serem consumidos por leveduras e transformados em álcool. A cana-de-açúcar, por sua vez, fornece os açúcares nas suas formas mais simples em seu caldo, dispensando tratamentos prévios, que consomem energia e prejudicam o balanço energético, além de tornar o processo mais caro.

Além disso, por ser uma gramínea, de alto potencial de produção de biomassa por hectare, a cana poderá ter sua produtividade dobrada através do uso do bagaço hidrolisado para a produção de álcool. Atualmente o bagaço é utilizado como combustível em caldeiras para a geração de energia elétrica. Considerando o potencial da produção de energia pela cana-de-açúcar, esta certamente será propagada para países localizados próximo aos trópicos, com o objetivo de gerar combustível a baixo custo. Esses países já estão recebendo investimentos nesse sentido, adquirindo equipamentos e conhecimento do Brasil para começar a operar nos próximos anos.

Quanto ao biodiesel, a venda de tecnologia também é uma oportunidade. Se o conhecimento empregado foi primeiramente importado da Europa, hoje está em processo de aprimoramento para as condições nacionais de uso de etanol como reagente, em vez do metanol (derivado do petróleo), e emprego de matérias-primas diversas. Na Europa somente oóleo de canola é utilizado em larga escala para produzir biodiesel, enquanto no Brasil já são empregados óleos de soja, girassol, mamona, ácidos graxos residuais do refino do óleo de dendê e sebo bovino. A realidade brasileira se repetirá em outros países tropicais em desenvolvimento.

Aexpansão da produção de biocombustíveis para outros países além do Brasil vai ao encontro de seus interesses por dois motivos principais. Primeiramente, para o Brasil é interessante que o álcool se transforme em uma commodity para que ganhe espaço no mercado internacional. Para tanto, é necessário que um volume maior seja produzido, e a diversidade de fornecedores aprimorada, além de se padronizar os combustíveis produzidos no mundo. O segundo motivo é referente à oportunidade de vender máquinas, equipamentos, variedades agrícolas e serviços para os países que adotarem a produção de biocombustíveis como parte de sua economia.

As principais discussões no ambiente internacional estão voltadas para a garantia da qualidade dos biocombustíveis e da sustentabilidade dos processos produtivos. O estabelecimento de padrões de qualidade diferentes por região pode se traduzir em uma formidável barreira técnica em países que queiram proteger o mercado interno do produto estrangeiro.

Somente após países que não produzem uma gota de álcool (ou têm produção irrelevante), tais como Japão e os da UE, passarem a discutir seus próprios padrões de qualidade, o Brasil, através do Inmetro em parceria com alguns institutos de pesquisa, começou a desenvolver o padrão de qualidade brasileiro do álcool para exportação. Essa é uma iniciativa importantíssima para que o Brasil participe do processo de formatação de um padrão internacional, de maneira que possa argumentar a favor de seus próprios critérios.

O processo de definição de padrões de qualidade de biocombustíveis é muito complexo, pois exigirá a definição de padrões mínimos universais. A inexistência desses padrões inviabiliza a transformação desse produto em commodity. No entanto, como podem ser utilizados diversas matérias-primas e processos industriais para a produção do mesmo biocombustível, a inexistência de padrões internacionais pode permitirque barreiras não tarifárias à entrada do produto estrangeiro sejam estabelecidas a partir da definição de padrões de qualidade que favorecem o produto doméstico. No caso do álcool, por exemplo, o Brasil produz $100 \%$ à base de cana-de-açúcar, enquanto os EUA produzem principalmente à base de milho e a UE pretende produzir à base de açúcar de beterraba.

No caso do biodiesel são claras as discrepâncias entre os padrões de qualidade, como é o caso do nacional, que não garante que esse combustível seja aceito na Europa, 
onde o padrão predominante é o alemão, muito mais restritivo que o brasileiro. $\mathrm{O}$ padrão de qualidade criado pela ANP para o biodiesel visou a incluir o uso de todas as matérias-primas possíveis, inclusive a mamona, que possui características físicoquímicas muito particulares, tais como a alta viscosidade. Além disso, no Brasil se produz biodiesel reagindo diversos tipos de óleo com metanol ou etanol, enquanto na Europa, maior produtor de biodiesel do mundo, sóé utilizado óleo de canola reagido com metanol, o que torna possível adotar padrões de qualidade muito mais restritivos. A importância do padrão de qualidade é assegurar o melhor rendimento do motor e garantir sua durabilidade, e qualquer outro critério aplicado além desses somente virá a prejudicar os consumidores de biodiesel.

Sistemas de certificação de sustentabilidade ambiental específicos para biocombustíveis estão sendo desenvolvidos, estando em evidência os sistemas em pesquisa no Reino Unido e na Holanda. Esses sistemas terão a difícil tarefa de avaliar simultaneamente o balanço energético do processo produtivo, o balanço da emissão de gases do efeito estufa, o desempenho ambiental, além de terem inserido critérios de avaliação de aspectos sociais da produção.

A maior preocupação da comunidade internacional quanto ao aumento da oferta de biocombustíveis pelo Brasil está relacionada ao risco de causar o aumento das taxas de desmatamento da Floresta Amazônica. Diversas iniciativas do governo brasileiro e de instituições de apoio estão sendo tomadas para brecar o desmatamento, tais como: a) aprimoramento das políticas de ordenamento territorial; b) implantação de políticas de zoneamento ecológico-econômico; c) aumento da eficiência da fiscalização. Relacionada a essa última medida, a Folha de S. Paulo de 22 de agosto de 2007 divulgou um estudo do Instituto do Homem e Meio Ambiente da Amazônia (Imazon) que sugere uma atitude trivial para brecar o desmatamento da Floresta Amazônica: aumentar em 28 vezes a eficiência de cobrança das multas aplicadas pelo Instituto Brasileiro do Meio Ambiente e dos Recursos Naturais
Renováveis (Ibama), que hoje é de 2,5\%. Muitas das multas não são recebidas porque o departamento jurídico não consegue acompanhar adequadamente os trâmites na justiça, que são muitos. O aprimoramento do departamento jurídico para aumentar a eficiência de cobrança para $70 \%$, segundo o Imazon, inviabilizaria o desmatamento nessa região.

As respostas às críticas aos biocombustíveis como forma de promovê-los devem levar em conta que algumas dessas críticas não condizem com a realidade ou não são devidamente tratadas internamente. Como diz Paulo Skaf no artigo mencionado no início deste texto, "considerar empecilho uma possível ocorrência de trabalho escravo é um despropositado exagero, considerando que o Brasil tem democracia consolidada e leis severas contra a exploração indevida de recursos humanos. É óbvio que, se o problema ocorrer de modo pontual, como pode acontecer em qualquer lugar do mundo, os culpados deverão ser detidos, julgados e apenados".

No ambiente internacional neste momento, mais importante que ficar se justificando, é ser ativo para contornar as barreiras ao mercado que estão sendo colocadas. Se o país não apresentar argumentos contundentes contra algumas medidas que estão sendo tomadas no ambiente internacional, pode perder espaço para as plantas industriais instaladas em outros países. Para essas indústrias, o interessante é manter o atual fluxo de commodities tais como a soja, que pode ser utilizada como matéria-prima para a produção de combustíveis, com valor agregado maior. Essas indústrias têm influência sobre a formação de políticas públicas em seus países, e junto com os agricultores são responsáveis pelo lobby que visa a dificultar a entrada do produto estrangeiro. Para o Brasil e demais países é uma perda manter sua posição de fornecedor de commodities agrícolas de baixo valor agregado em detrimento de produtos acabados, como é o caso dos biocombustíveis. Além dos biocombustíveis em si, a proteína presente no farelo de grãos pode ser comercializada na forma de ração animal, produto que tem sido 
sistematicamente valorizado no mercado internacional, principalmente após os Estados Unidos, maior produtor mundial de milho, terem passado a utilizar esse cereal como matéria-prima para a produção de mais de 20 bilhões de litros de álcool por ano.

\section{CONCLUSÃ̃O}

O mundo tem muito a lucrar com a substituição de parte dos combustíveis fósseis por biocombustíveis, tal como na redução da emissão dos gases do efeito estufa, maior segurança no suprimento do combustível e oportunidade de desenvolvimento em países que podem expandir suas atividades agroindustriais. Porém, é necessário uma política global para que ocorra o aproveitamento dos reais potenciais desses biocombustíveis. Enquanto não houver o uso comercial dos biocombustíveis de segunda geração, o potencial dos países europeus e dos Estados Unidos de produzirem seus próprios biocombustíveis sem trazer efeitos maléficos, tais como degradação ambiental e impacto sobre preços dos alimentos, é muito baixo.

Nessa fase, é importante consolidar o mercado internacional para os biocombustíveis de forma que outros países, principalmente da América Latina e da África, de alto potencial de produção de biomassa, possam começar a atuar. Com a adoção de novas tecnologias os países desenvolvidos poderão aumentar sua pro- dução com base no uso de matérias-primas provenientes de descartes da agroindústria, além da reciclagem de resíduos em geral. Nem por isso o potencial dos países em desenvolvimento para a produção de biomassa ficará inutilizado, pois o mercado para combustíveis é inviável de ser completamente abastecido a partir de biocombustíveis. A produção atual atende menos de $1 \%$ da demanda global por combustíveis e o mercado nunca estará saturado desse produto.

O objetivo desse processo é diversificar a matriz energética e desenvolver novas tecnologias que contornem o problema dos impactos ambientais do uso do petróleo e o seu aumento sistêmico de preço devido à escassez. Sobretudo, uma cooperação internacional pode resultar em desenvolvimento para diversos países, através da adoção de políticas públicas bem-estruturadas para promoção da geração de renda e inclusão social.

O Brasil desponta como um grande líder nesse setor por ter experiência em políticas públicas de incentivo aos biocombustíveis, além de tecnologia de produção e uso. A comunidade internacional deve discutir e implementar um sistema regulatório que permita moldar o produto para atender à demanda da sociedade, que está cada vez mais exigente quanto à sustentabilidade do que se consome. Uma discussão internacional franca pode trazer muitos dividendos para a sociedade, mas para isso precisamos conseguir ultrapassar as barreiras hoje existentes. 